\title{
Evaluating Musical Software Using Conceptual Metaphors
}

\author{
Katie Wilkie \\ Centre for Research in Computing \\ Open University \\ Milton Keynes, MK7 6AA \\ +44 (0)1908 274066 \\ klw323@student.open.ac.uk
}

\author{
Simon Holland \\ The Computing Department \\ Open University \\ Milton Keynes, MK7 6AA \\ +44 (0)1908 332570 \\ s.holland@open.ac.uk
}

\author{
Paul Mulholland \\ Knowledge Media Institute \\ Open University \\ Milton Keynes, MK7 6AA \\ +44 (0)1908 654506 \\ p.mulholland@open.ac.uk
}

\begin{abstract}
An open challenge for interaction designers is to find ways of designing software to enhance the ability of novices to perform tasks that normally require specialized domain expertise. This challenge is particularly demanding in areas such as music analysis, where complex, abstract, domain-specific concepts and notations occur. One promising theoretical foundation for this work involves the identification of conceptual metaphors and image schemas, found by analyzing discourse. This kind of analysis has already been applied, with some success, both to musical concepts and, separately, to user interface design. The present work appears to be the first to combine these hitherto distinct bodies of research, with the aim of devising a general method for improving user interfaces for music. Some areas where this may require extensions to existing method are noted.

This paper presents the results of an exploratory evaluation of Harmony Space, a tool for playing, analysing and learning about harmony. The evaluation uses conceptual metaphors and image schemas elicited from the dialogues of experienced musicians discussing the harmonic progressions in a piece of music. Examples of where the user interface supports the conceptual metaphors, and where support could be improved, are discussed. The potential use of audio output to support conceptual metaphors and image schemas is considered.
\end{abstract}

\section{Categories and Subject Descriptors}

H5.2. Information interfaces and presentation (e.g., HCI): User Interfaces: Theory and methods.

\section{General Terms}

Design, Human Factors, Theory.

\section{Keywords}

Embodied cognition, image schemas, conceptual metaphors, user interface design, tonal harmony, Harmony Space.

\section{INTRODUCTION}

Music is an intrinsic part of our culture. It is used to aid relaxation; reflect the mood of social situations; as an accompaniment to religious services; and to enhance the appeal

(C) The Author 2009.

Published by the British Computer Society of interaction designs through incorporating audio output as part of the interaction model - for example when moving a file to the trash can. Pervasive though music is, technical understanding of the medium and specifically how it is constructed, is usually restricted to those with specialist domain knowledge. Harmonic progression in particular is a difficult concept to grasp as it involves knowledge of domain-specific terminology and notation. However, if we can establish a means by which we can translate the specialist knowledge used by domain experts when analysing an excerpt of music into a user interface which effectively communicates this information, exploiting pre-existing embodied knowledge and experience, it may be possible to systematically improve the quality of interaction designs to better support the transition from novice to domain expert.

One promising theory for analysing abstract concepts such as harmonic progression uses the conceptual metaphors exposed through language to identify a number of constructs named image schemas. These image schemas, characterised by Johnson as "recurring patterns of our sensory-motor experience", provide people with the ability to structure abstract concepts by applying perceptions of their sensory-motor experiences of space, orientation, forces and interactions with other bodies to different domains [8]. Hurtienne and Blessing [5] have concluded that designing interactions which conform to simple conceptual metaphors such as MORE IS UP - a metaphorical extension of the UP-DOWN image schema appears to lead to a more intuitive interaction model. More recent work by Hurtienne, Israel and Weber concluded that identifying the image schemas elicited through the context-ofuse-analysis helped to focus the design process on the essential user interface requirements [7]. We hypothesise that if we can establish the conceptual metaphors used by domain experts when discussing harmonic progression in an excerpt of music, we can use these metaphors and their constituent image schemas to identify improvements to user interfaces for analysing harmonic progression.

This paper presents the results of an exploratory evaluation of Harmony Space, a tool for playing, analysing and learning about harmony [2]. The goal of the evaluation is to establish the extent to which Harmony Space supports the conceptual metaphors and image schemas used by experienced musicians when engaged in the task of analysing a short excerpt of music. Examples of where the user interface supports the conceptual metaphors, and where support can be improved, will be discussed, and the potential use of audio output to support conceptual metaphors and image schemas will be considered. 


\section{BACKGROUND}

Increasing evidence exists to support the central claim of embodied cognition theorists; namely that the interactions between our bodies and the environment in which they exist play an important role in the development of cognitive abilities [12]. However, the physiological properties of the body are not solely responsible for the development of the embodied mind; the social and cultural environment in which the body is situated also plays a significant role by providing additional contextual information which can affect the processing of perceptual stimuli [12].

Language, an inherent part of our cultural and social heritage, plays a substantial role in cognition. Analysis of spatial expressions used in language has identified the importance of repeating patterns of bodily experience named image schemas in the development of linguistic and conceptual models [13]. One concept prevalent in language is that of one object containing another. For example the phrases "put the toys in the box", "he walked into the auditorium" or "she is in a bad mood" all make reference to one entity being contained by another, even if that containing entity does not fully enclose its contents or is not a physical container in its own right. All of these examples which are claimed to be based on sensory-motor experiences of containment, make use of the CONTAINER image schema, a visual representation of which is shown in Figure 1 below. Several image schemas have been identified and can be classified into a number of groups whose base sensory-motor experiences include the concepts of containment, space and force [6].

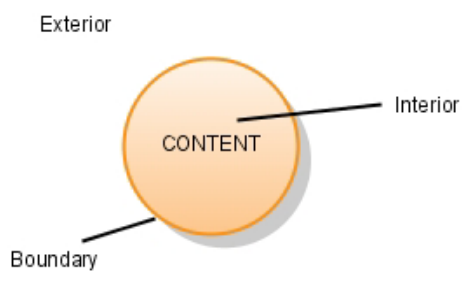

\section{Figure 1 - Representation of the CONTAINER image schema}

Image schemas can be applied to more abstract concepts, through the process of cross-domain mapping, creating conceptual metaphors [10]. For example the phrase "He's going $\boldsymbol{u} \boldsymbol{p}$ in the world" demonstrates the mapping of the UP-DOWN image schema onto the more abstract concept of career progression, creating the conceptual metaphor PROMOTION IS UP; progressing in one's career, i.e. being promoted, is likened to being physically above other people. A visual representation of the UP-DOWN image schema is shown in Figure 2 below.

This ability to extend the application of image schemas through conceptual metaphors to other, potentially unrelated domains, makes them an extremely flexible and powerful construct as well as a useful tool for analysing conceptual models. Several applications of conceptual metaphor and image schema theory exist, including arithmetic, politics and philosophy [9]. Some initial attempts have been made to apply conceptual metaphor and image schema theories to the domains of musical analysis and user interface design respectively which will be discussed in the following sections.

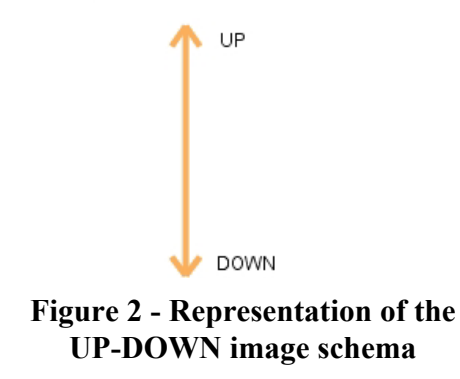

2.1 Music

The most comprehensive example of applying image schema theory to the domain of music is provided by Saslaw's analysis of the language used in Riemann's treatise entitled "Systematic Study of Modulation as a Foundation for the Study of Musical Form" [14]. Salsaw argues that Riemann understands harmonic progression and modulation as movement along a path from one key CONTAINER to another using the SOURCE-PATHGOAL image schema. A visual representation of the SOURCEPATH-GOAL image schema is shown in Figure 3 below. Saslaw further extends the argument stating that based on Riemann's conceptual models, modulation requires a FORCE image schema to move from one key CONTAINER to another.

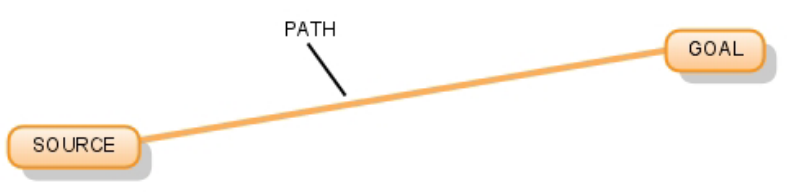

Figure 3 - Representation of the SOURCE-PATH-GOAL image schema

Saslaw's study is complemented by Zbikowski's paper on conceptual models and cross-domain mapping in music theory [15]. Zbikowski compares and contrasts three theorists' analyses of a short phrase from the first movement of Mozart's A major piano sonata, K331 with a view to understanding their conceptual models of music. Although he identifies similarities between the analyses he also discovers differences in their approach to organising the structure of music, which he attributes to the theorists having different conceptual models of hierarchy. He concludes his paper by discussing the process of mapping the different conceptual models of hierarchy onto aspects of musical structure.

\subsection{User Interface Design}

Although metaphors are often considered an important aspect of user interface design, using conceptual metaphor and image schema theory as part of the design process is a relatively new technique. In a recent paper Hurtienne and Blessing [5] seek to establish if image schema theory can provide a new approach to user interface design. They argue that if their approach is successful, employing it would lead to more intuitive user interfaces, as image schemas are based on sensory-motor experiences. The preliminary experiments discussed in the paper certainly appear to support this hypothesis. For example, in one experiment to test the conceptual metaphor MORE IS UP, characterised by phrases such as "his salary went up", a vertically oriented slider control was used to represent quantity and participants were asked to set the slider value based on a series of words associated with quantity. The response times of the participants were reduced when the scale of the slider was oriented upwards supporting the metaphor than when it was oriented downwards contrary to the metaphor. However, only a small subset of image schemas and conceptual metaphors were 
tested and further work is necessary to clarify if the hypothesis is sound. Further work by Hurtienne, Israel and Weber into redesigning an invoice verification and posting application concluded that using the image schemas elicited through the context-of-use-analysis as a meta-language for the analysis and design processes helped to focus on the essential user interface requirements [7].

Although increasing evidence exists to support the successful application of image schema and conceptual metaphor theory to both musical analysis and (separately) user interface design, no attempt has been made, to our knowledge, to apply these theories to user interfaces for musical analysis. The complex domain terminology and notation used particularly in harmonic analysis, differentiates user interfaces for this domain from those for business applications such as the invoice verification and posting application investigated by Hurtienne et al [7], not only in terms of requirements, but also in the method used to effectively communicate the domain specific concepts to novice users, as explored below.

Information on the conceptual metaphors and image schemas used by musical experts already exists as discussed earlier [14] [15], however these analyses are based on the language used by theorists in written work. Writing such articles and books requires significant time and thought, and it is likely the content will have been subject to a review and editorial process, meaning the conceptual models and metaphors exposed could, to a certain extent, be masked by other, literary factors. In order to elicit a more spontaneous collection of conceptual metaphors a short study was designed.

\section{STUDY DESIGN}

A short study was conducted in order to establish the conceptual metaphors used by domain experts when analyzing an excerpt of music. Three experienced musicians, all of whom have been educated to at least undergraduate level in music and have experience in performing and conducting (and in two cases instrumental music teaching), were chosen to take part in the study. They were provided with a score of the first twentytwo bars of "Laudate Dominum", a sacred motet for six voices, strings and basso continuo by Claudio Monteverdi, an Italian composer active between the later years of the $16^{\text {th }}$ and first half of the $17^{\text {th }}$ centuries. The excerpt was chosen as the harmonic progression is simple enough to easily establish, but the excerpt also exhibits a mixture of lively melodies and homophonic movement, providing ample opportunity to expose the conceptual metaphors used through discussion of the excerpt.

The participants were asked to collaborate on answering a number of questions:

○ Discuss the melodic movement in this excerpt.

- Discuss the harmonic progression in this excerpt.

- Discuss the interplay between the instrumental and vocal parts.

- Discuss how you feel about this piece of music.

- Identify an aspect of this excerpt that you find interesting and describe why.

These questions were designed to focus the participants on discussing specific aspects of the excerpt and thus maximize the number of conceptual metaphors and constituent image schemas likely to be elicited from the dialogue. The participants were asked to collaborate rather than answer the questions individually as it was believed that collaboration would produce more spontaneous discussion as the participants evaluated each other's responses, revealing a greater wealth of conceptual metaphors. The lyrics for the vocal parts, title and composer's details were obscured to ensure they did not affect the participants' interpretation of the excerpt.

The discussion lasting approximately thirty minutes was recorded and the transcription analysed to identify the conceptual metaphors used by the participants, comparing the comments made with linguistic examples given in [4] [7] [5] [6] [8] [9]. A large number of conceptual metaphors relating to various aspects of music were exposed, however for this study only those specifically relating to harmonic analysis were considered. A selection of the comments and candidate conceptual metaphors provisionally identified along with their constituent image schemas appears in table 1 below.

Table 1 - Table showing the conceptual metaphors and their constituent image schemas exposed by the dialogue.

\begin{tabular}{|c|c|c|}
\hline Comment & $\begin{array}{l}\text { Conceptual } \\
\text { Metaphor(s) }\end{array}$ & $\begin{array}{l}\text { Constituent } \\
\text { Image Schemas }\end{array}$ \\
\hline $\begin{array}{l}\text { “... it just jumps } \\
\text { from G into } \\
\text { C...and then A } \\
\text { minor...then D } \\
\text { minor...then back } \\
\text { to G major..." }\end{array}$ & $\begin{array}{l}\text { HARMONIC } \\
\text { PROGRESSION IS } \\
\text { MOVEMENT } \\
\text { ALONG A PATH } \\
\text { A CHORD IS A } \\
\text { CONTAINER } \\
\text { [FOR NOTES] }\end{array}$ & $\begin{array}{l}\text { SOURCE-PATH- } \\
\text { GOAL } \\
\text { CONTAINER }\end{array}$ \\
\hline $\begin{array}{l}\text { "...they just go } \\
\text { back to the tune } \\
\text { again straight } \\
\text { away in A } \\
\text { minor..." }\end{array}$ & $\begin{array}{l}\text { A KEY IS A } \\
\text { CONTAINER FOR } \\
\text { NOTES }\end{array}$ & CONTAINER \\
\hline $\begin{array}{l}\text { "...I'd say I'd } \\
\text { modulated to } \\
\text { something else." }\end{array}$ & $\begin{array}{l}\text { MODULATION IS } \\
\text { MOVEMENT } \\
\text { ALONG A PATH }\end{array}$ & $\begin{array}{l}\text { SOURCE-PATH- } \\
\text { GOAL }\end{array}$ \\
\hline $\begin{array}{l}\text { "...I like the bit } \\
\text { where it goes } \\
\text { down to E } \\
\text { major." }\end{array}$ & $\begin{array}{l}\text { LOW PITCH IS } \\
\text { DOWN }\end{array}$ & UP-DOWN \\
\hline $\begin{array}{l}\text { "...as you say you } \\
\text { think you know } \\
\text { what's coming } \\
\text { and then..." }\end{array}$ & $\begin{array}{l}\text { A CHANGE IN } \\
\text { MUSICAL STYLE } \\
\text { IS A CHANGE IN } \\
\text { DIRECTION }\end{array}$ & DIVERSION \\
\hline $\begin{array}{l}\text { "The other parts } \\
\text { stay on almost the } \\
\text { same note all the } \\
\text { way through." }\end{array}$ & $\begin{array}{l}\text { A NOTE IS AN } \\
\text { OBJECT }\end{array}$ & OBJECT \\
\hline $\begin{array}{l}\text { "D major chord } \\
\text { stuck in there at } \\
\text { the end..." }\end{array}$ & $\begin{array}{l}\text { A CHORD IS AN } \\
\text { OBJECT }\end{array}$ & OBJECT \\
\hline
\end{tabular}

It is interesting to note that these conceptual metaphors were not isolated and were repeated a number of times throughout the dialogue, reinforcing their importance as part of the conceptual models the participants used to interpret and understand the excerpt. Additionally the conceptual metaphors HARMONIC PROGRESSION IS MOVEMENT ALONG A PATH, MODULATION IS MOVEMENT ALONG A PATH and A KEY IS A CONTAINER FOR NOTES are confirmed by Saslaw's research into the image schemas identifiable in Riemann's "Systematic Study of Modulation as a Foundation for the Study of Musical Form" [14]. The conceptual metaphor LOW PITCH IS DOWN was identified by Zbikowski [15] although he makes reference to the VERTICALITY image schema rather than using the UP-DOWN image schema. This conceptual metaphor was also noted by Hurtienne [4].

Other interpretations of the dialogue are possible since many image schemas have dependencies on or are related to other 
image schemas, for example a CONTAINER schema will have an associated CONTENT schema. In particular, comments made by some participants indicate that FORCE schemas could form part of their conceptual models. This is supported by Saslaw who argues that Riemann's theories require a FORCE schema to modulate to another key [14]. Finally, there may be evidence for additional image schemas such as NEAR-FAR and PART-WHOLE in the data [Hurtienne, personal communication].

\section{APPLICATION OF FINDINGS}

\subsection{Application to a musical user interface}

An exploratory attempt was made to investigate whether the conceptual metaphors and image schemas identified had been applied, unconsciously or otherwise, to the interaction design and structure of the user interface of Harmony Space. We anticipate that later work will include a comparative study of this kind across several musical interfaces - but for the purposes of this first study we opted to focus on a single musical interface.

Harmony Space is based on the Longuet-Higgins [11] and Balzano [1] theories of harmonic perception and is specifically designed to assist novices in learning about the principles of tonal harmony and harmonic progression [2]. Harmonic theory requires a complex set of concepts to master as it involves knowledge and understanding of a number of domain specific terms and notation. Harmony Space attempts to remedy this problem by exploiting users' basic understanding of straightline movement and collections of related entities. A whole body floor-projected version of Harmony Space exists [3], however the desktop version of the application was used for this evaluation.

Harmony Space uses a two-dimensional grid to display all of the notes within the chromatic scale. The notes within a specific key (a subset of notes within the chromatic scale) are arranged within the repeated pattern of a white key window. Figure 4 below shows an annotated screenshot of Harmony Space with the key window configured to show the notes within the key of $\mathrm{G}$ major. Notes which do not form part of the selected key appear within the "forbidden" black areas.

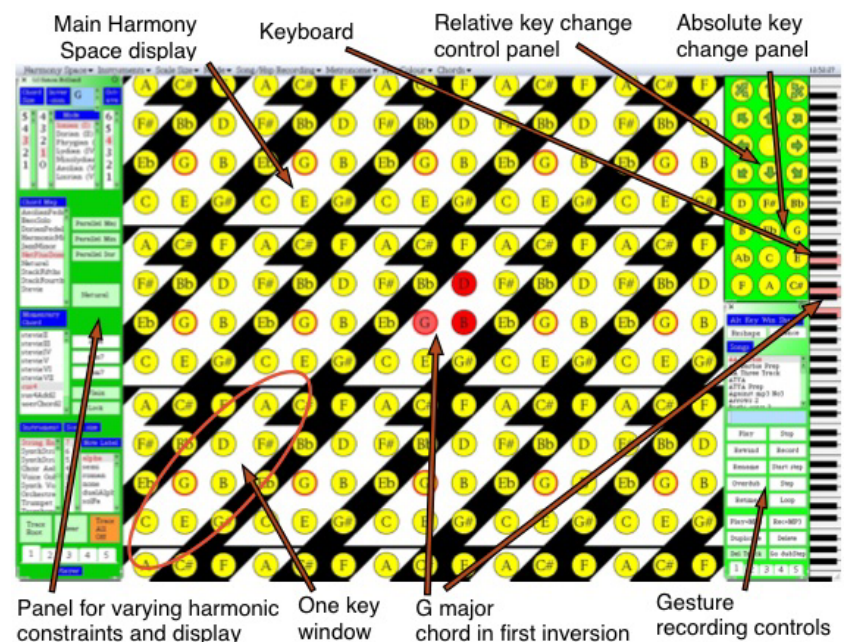

Figure 4 - Screenshot of Harmony Space configured in G major
When the user clicks on a note within the key window the appropriate chord is sounded. The tonal quality of the chord, major, minor or diminished, will depend on the notes available in the selected key. For example, under the default mapping, when configured in $\mathrm{G}$ major, clicking on $\mathrm{G}$ will play the chord of $\mathrm{G}$ major, clicking on $\mathrm{C}$ will play the chord of $\mathrm{C}$ major and clicking on $\mathrm{E}$ will play the chord of $\mathrm{E}$ minor, etc, etc.

\subsection{Evaluation}

Evaluating Harmony Space using the conceptual metaphors and image schemas identified in the earlier study revealed the majority of the metaphors and image schemas are supported either through visual display, interaction components or through audio output. Although audio output is a common feature of most, if not all, music software, the support for the conceptual metaphors and image schemas through audio output has not been systematically investigated to our knowledge, and is therefore particularly interesting in this instance. The metaphor A CHORD IS A CONTAINER [FOR NOTES] is supported by sounding all of the notes in a chord at the same time. The metaphor is then reinforced by highlighting the notes in the chord on the piano keyboard and on the grid display. Since Hurtienne et al's studies did not consider audio output, [5], [7] this evaluation of Harmony Space provides us with additional information on new ways in which conceptual metaphors and image schemas can be applied to user interface design, however further work is required to establish the extent to which audio output can be used in this manner.

Two conceptual metaphors that Harmony Space supports well are HARMONIC PROGRESSION IS MOVEMENT ALONG A PATH and MODULATION IS MOVEMENT ALONG A PATH. By tracing the history of the note circles clicked on the user can start to visualise chord changes as a series of points along a path. (For example figure 5 shows the harmonic progression through Charlie Parker's Swedish Blues. Circles coloured red indicate a chord used in the excerpt and the arrows indicate the direction of the progression from one chord to another. Note the arrows have been added to the figure independently.) Modulation through moving the key window to a different key provides a similar conceptual model. Useful though that support is, it could however be improved by the addition of a means of tracing the direction of both the chord changes and the key window. This addition would help to cement the conceptual metaphors further and should aid users in memorising the sequences.

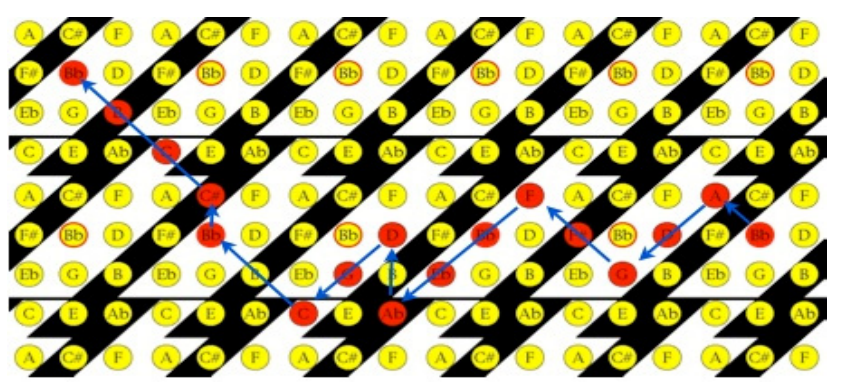

Figure 5: Harmonic progression in Charlie Parker's Swedish Blues. Arrows are used to show the PATH of the progression through the piece.

Unfortunately the conceptual metaphor LOW PITCH IS DOWN is not supported in the current version of Harmony Space (at least, not in the central two-dimensional grid area though it is represented in the subsidiary vertical keyboard 
display area - see figure 4). Viewing a composition in a score format affords the development of the concept of one chord being higher or lower than another (figure 6) based on the pitches of the notes included in the chords - though this can be ambiguous or undefined, in cases where some notes are lower and some higher. In the study, where participants were given an excerpt in score format, several instances were recorded of chord progressions being referred to as moving up and down from one chord to another. Since Harmony Space displays each note in the chromatic scale in a grid format, where both major axes encode harmonic relationships, rather than in a score format, where the vertical position of the notes indicates pitch height, it does not appear to be straightforwardly possible to provide support for this particular conceptual metaphor in this part of the interface.

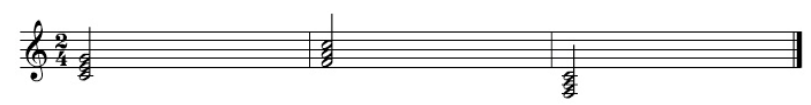

Figure 6: Stave showing a $\mathrm{C}$ major chord and two $\mathrm{F}$ major chords, the second is one octave lower than the first.

For many purposes, the absence of support for this metaphor in the central display may not matter, as the primary aim of this interface is to afford understanding and manipulation of harmonic relationships and harmonic movement - in the case of beginners, focusing on basic relationships; and in the case of experts, focusing on larger scale harmonic relationships. Indeed, for many purposes, the interface explicitly assumes octave equivalence [2]. However, when dealing specifically with certain aspects of voicing and voice leading (tasks which concern the melodic movement of individual parts within a harmonic whole) the lack of support for the pitch height metaphor in the central display is likely to make that relationship less immediately obvious, making some tasks of this kind harder.

One further detail illustrates issues of combinations of, and trade-offs between, metaphors in interface design. In the central display area, pitch differences of less than an octave are encoded as distances and directions in the 2D plane, although LOW PITCH is not represented as DOWN in the current design. For pitch differences greater than an octave, the octave component is displayed using what might be seen as a variant of the LOW PITCH IS DOWN metaphor, with "down" oriented in the z-plane. However, crucially, since the interface is rendered graphically in two dimensions, the z-plane is portrayed indirectly using shading (figures $7 \mathrm{a}$ and $\mathrm{b}$ ), so that perceptually this presents as a LOW PITCH is DARK conceptual metaphor. See [4] for more on the BRIGHT-DARK
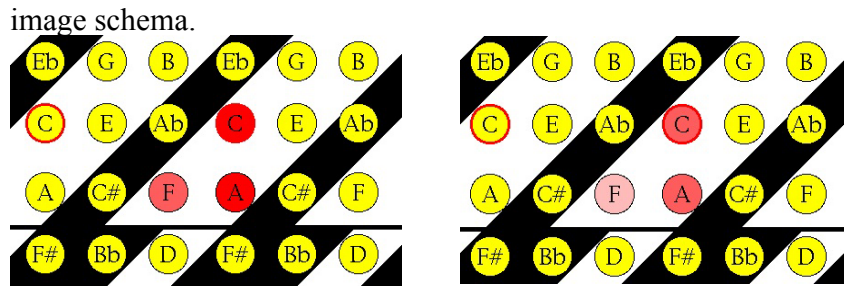

Figures 7a and b. An F major chord in 1st inversion. The $F$ major chord in figure $7 \mathrm{a}$ is an octave higher than in $7 \mathrm{~b}$.

\subsection{Design Implications}

After completion of the analysis, the results were shown to the designer. This was to contribute to the design process and to elicit informal preliminary information on the perceived value of the approach to a designer. The designer stated that he considered the criticisms insightful, although he was already aware of the problems identified. He had pre-existing design sketches pending implementation which partly address these problems.

The effect of the first design sketch was simply to add an area for tracing key changes. The effect of the second (figure 8) was to apply a rotation and reflection operation to the graphical layout of the central area, whose effect was to make the metaphor LOW PITCH IS DOWN hold on any vertical slice of the $2 \mathrm{D}$ plane.

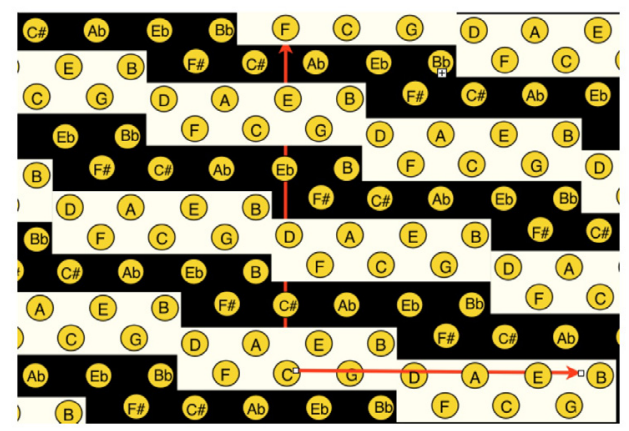

Figure 8 - Redesign of Harmony Space

Even with this improved partial support of the pitch height metaphor, short of moving to a three dimensional graphical rendering, the criticism about the clarity of the metaphor still has application in the central display area, in the case of intervals greater than an octave and near octave boundaries, for reasons analysed at the end of section 4.2.

\section{CONCLUSIONS}

\subsection{Limitations}

Due to the labour involved in this first application of this method, only a single excerpt of music was considered. Using a number of excerpts in different genres would help to confirm, falsify or refine the interpretation of the comments made by participants in this study and also afford the opportunity to elicit additional conceptual metaphors and image schemas which were not identified in this study.

\subsection{Further Work}

The identification of the conceptual metaphor LOW PITCH IS DOWN, which is supported by the vertical placement of notes within a score format, indicates that alternative styles of musical presentation, and indeed different tasks, may elicit different conceptual metaphors. Specifically if the participants had been asked to analyse the excerpt using Harmony Space rather than being provided with a score, it is possible that conceptual metaphors based on the UP-DOWN schema may not have been exposed through the resulting dialogue, as the central display of Harmony Space does not support them. Conversely, other conceptual metaphors, for harmonic relationships not considered in the present study, but which Harmony Space may represent well, might have been revealed.

Future work will focus on using alternative musical representation formats, for example piano roll notation, guitar tablature, figured bass and video footage of performances, to establish if different representation formats do indeed expose different conceptual metaphors. Some consideration will also be given to the role played by visual metaphors and semiotics using a particular representation format. The results of these studies will be used to systematically analyse further examples 
of music analysis software. Further studies will also seek to clarify the existence of FORCE schemas as indicated in the initial study and Saslaw's work [14].

\subsection{Conclusions}

This study is the first that we are aware of to apply image schema and conceptual metaphor theory to user interface design for music. We have identified and analysed conceptual metaphors used by domain experts when discussing harmonic progression in an excerpt of music. We have analysed the extent to which these conceptual metaphors and image schemas have been applied, unconsciously or otherwise, to the design of a user interface for music (Harmony Space).

This analysis identified a number of conceptual metaphors and image schemas that were supported in the user interface. It also revealed parts of the user interface present design in which opportunities to apply users' conceptual metaphors fully or consistently were not realized. This led to the identification of areas for potential improvement to the user interface. These areas for improvement were found to be already known to the designer, but the analyses were considered insightful by the designer, and in any case we have presented a systematic, independent method to identify several such critical features of a user interface for music.

The evaluation also revealed the potential for a new area of application of conceptual metaphors and image schemas to user interface design, namely that of audio output. A larger scale study is required to establish the extent to which audio output can support conceptual metaphors and image schemas. However, the results from this preliminary study suggest this could be a fruitful area for future investigation.

\section{ACKNOWLEDGEMENTS}

We gratefully acknowledge the feedback on this paper provided by Jörn Hurtienne.

\section{REFERENCES}

[1] Balzano, G. J. The Group-theoretic Description of 12-fold and Microtonal Pitch systems. COMPUTER MUSIC JOURNAL, 4, 4 (Winter 1980).

[2] Holland, S. Learning about harmony with Harmony Space: an overview. In Smith, M. and Wiggins, G. eds. Music Education: An Artificial Intelligence Approach, 1994.

[3] Holland, S., Marshall, P., Bird, J., Dalton, S., Morris, R., Pantidi, N., Rogers, Y. and Clark, A. Running up Blueberry Hill: Prototyping Whole Body Interaction in Harmony Space. In Proceedings of the Third Conference on Tangible and Embodied Interaction. (2009). ACM, New York, 2009, 92-98.
[4] Hurtienne, J. ISCAT - Image Schema Database. (2007). Available at http://iscat.zmms.tu-berlin.de:8080/iscat/ [Accessed February 2009].

[5] Hurtienne, J. and Blessing, L. Design for Intuitive Use Testing Image Schema Theory for User Interface Design. In International Conference on Engineering Design. (Paris, France, 2007).

[6] Hurtienne, J. and Israel, J. H. Image schemas and their metaphorical extensions: intuitive patterns for tangible interaction. In Proceedings of the 1st International Conference on Tangible and Embedded Interaction. (Baton Rouge, Louisiana, February 15 - 17, 2007). ACM, New York, 2007, 127-134.

[7] Hurtienne, J., Israel, J. H. and Weber, K. Cooking up Real World Business Applications Combining Physicality, Digitality, and Image Schemas. In Proceedings of the 2nd International Conference on Tangible and Embedded Interaction. (Bonn, 2008). ACM, New York, 239-246.

[8] Johnson, M. The philosophical significance of image schemas. In Hampe, B. and Grady, J. eds. From Perception to Meaning: Image Schemas in Cognitive Linguistics. Walter de Gruyter, Berlin, 2005, 15-33.

[9] Lakoff, G. and Johnson, M. Metaphors We Live By. The University of Chicago, London, 2003.

[10] Lakoff, G. and Nunez, R. E. Conceptual Metaphor. In Where Mathematics Comes From: How the Embodied Mind Brings Mathematics Into Being. Basic Books, United States of America, 2000, 39-48.

[11] Longuet-Higgins, H. C. Letter to a Musical Friend. Music Review, (1962), 244-248.

[12] Rohrer, T. The Body in Space: Dimensions of Embodiment. In Ziemke, T., Zlatev, J., Frank, R. and Dirven, R. eds. Body, Language, and Mind: Embodiment. Walter de Gruyter, Berlin, 2007, 339-378.

[13] Rohrer, T. Image Schemata in the Brain. In Hampe, B. and Grady, J. eds. From Perception to Meaning: Image Schemata in Cognitive Linguistics. Walter de Gruyter, Berlin, 2005, 165-196.

[14] Saslaw, J. Forces, Containers, and Paths: The Role of Body-Derived Image Schemas in the Conceptualization of Music. Journal of Music Theory, 40, 2 (Autumn 1996), 217-243.

[15] Zbikowski, L. M. Conceptual Models and Cross-Domain Mapping: New Perspective on Theories of Music and Hierarchy. Journal of Music Theory, 41, 2 (Autumn 1997), 193-225. 